\title{
ALTERNATE AND DIRECT CURRENT ANALYSIS OF CONCRETE
}

\author{
Rajdeep Srivastava ${ }^{1}$, Aruj Kaushik ${ }^{2}$, Radhkrishna ${ }^{3}$ \\ ${ }^{1}$ Undergraduate, Department of Civil Engineering, RV College of Engineering, Karnataka, India \\ ${ }^{2}$ Undergraduate, Department of Civil Engineering, $R V$ College of Engineering, Karnataka, India \\ ${ }^{3}$ Associate Professor, Department of Civil Engineering, RV College of Engineering, Karnataka, India
}

\begin{abstract}
We live in an era where houses and other institutional buildings are getting more and more automated and sophisticated; this boom in the construction industry is accompanied by an increasing risk of structural failures. This paper illustrates the determination of electrical properties of concrete for the purpose of structural health monitoring. Concrete blocks of size (150 $x$ $150 \times 150 \mathrm{~mm}$ ) were used as test specimen and 2-point probe method was used for plotting I-V characteristics, for both direct and alternating current supply. The semiconductor nature of cement matrix was studied as a combination of Resistance-Capacitance Circuit along with its applications. It was found that conductivity of concrete decreases on ageing in a definite pattern, and conductivity can be used to comment on durability and quality of concrete. However, under loading, an impedance jump is observed, owing to induction of cracks or voids in concrete.
\end{abstract}

Keywords: Conductance, Conductivity, Impedance, Resistance, and Durability.

\section{INTRODUCTION}

Recent priority on structural health monitoring has been rotating around the use of embedded or attached sensor, such as piezoelectric, optical fiber, Micro-ElectricalMechanical systems, dynamic response system, phase transformation, Capacitive and other embedded sensor systems. Popular real-time SHM techniques include the use of fiberoptics (Li et. al, 2004) and piezoelectric sensors (Giurgiutiu, 2007). However, the study of structural health of concrete using the electrical properties of concrete is fairly untouched.

In general, either 2-point probe or a 4-point probe is used to determine the characteristic curves. For measurements electrodes can either be mounted on the surface using conducting gel or can be placed into fresh concrete. The 2point probe method shows a time dependent reduction in conductivity resulting from accumulation of charges at the electrodes when connected to a direct current source. However, this demerit associated with charges was worked well by using alternating current source (Vilhunen et al., 2002).

Recent studies using electrical properties of concrete involve DC conductivity with setting time of Portland cement composites (Calleja et. al, 1953; Hammond and Robsonet. al, 1955). AC analysis has been studied with electrical impedance tomography (EIT). However, due to lack of proper validation the application remains questionable.

Though the already existing literature states that concrete exhibits semi-conductor as well as self-sensing properties, but the literature is silent about the existing RC circuit nature in the concrete bulk. This paper explores and studies the cement matrix as combination of resistances and capacitances for the purpose of structural health monitoring, and further investigates a quick alternative to test durability of concrete using $\mathrm{I}-\mathrm{V}$ characteristics and possible propagation of cracks of already existing or new cracks using peakcurrent analysis, and further validate the fact that conductivity is a material property and conductance is dependent on length.

\section{MATERIALS AND METHODS}

Cement (OPC 53 grade), fine aggregates, coarse aggregates and tap water were used to make concrete. Various specimens were cast using manufactured sand of grading zone II as fine aggregate. Also, $20 \mathrm{~mm}$ downsize and 12.5 $\mathrm{mm}$ downsize coarse aggregates were used. Properties of material are shown in Table 1 (a), 1 (b). Concrete mix was designed for M40 and M20 grade concrete and the mix proportions are tabulated in Table 2.

Table 1 (a): PRELIMINARY TEST RESULTS FOR AGGREGATES

\begin{tabular}{|l|l|l|}
\hline Type of Aggregate & $\begin{array}{l}\text { Specific } \\
\text { Gravity }\end{array}$ & $\begin{array}{l}\text { Fineness } \\
\text { Modulus }\end{array}$ \\
\hline Fine Aggregate & 2.64 & 2.628 \\
\hline Coarse Aggregate & 2.72 & 7.02 \\
\hline
\end{tabular}

Table 1 (b): PRELIMINARY TEST RESULTS FOR CEMENT

\begin{tabular}{|l|l|l|l|l|}
\hline $\begin{array}{l}\text { Grade } \\
\text { of } \\
\text { Cement }\end{array}$ & $\begin{array}{l}\text { Specific } \\
\text { Gravity }\end{array}$ & $\begin{array}{l}\text { Normal } \\
\text { Consistency } \\
\text { (min.) }\end{array}$ & $\begin{array}{l}\text { Initial } \\
\text { Setting } \\
\text { Time } \\
\text { (min.) }\end{array}$ & $\begin{array}{l}\text { Final } \\
\text { Setting } \\
\text { Time } \\
\text { (min.) }\end{array}$ \\
\hline $\begin{array}{l}\text { OPC } \\
53\end{array}$ & 3.1 & 30 & 125 & 480 \\
\hline
\end{tabular}


Table 2: MIX PROPORTIONS

\begin{tabular}{|c|c|c|c|c|c|c|}
\hline $\begin{array}{l}\mathrm{S} \\
1 . \\
\mathrm{N} \\
\text { o. }\end{array}$ & $\begin{array}{l}\text { Gra } \\
\text { de } \\
\text { of } \\
\text { conc } \\
\text { rete }\end{array}$ & $\begin{array}{l}\text { Ceme } \\
\mathrm{nt} \\
(\mathrm{kg} / \mathrm{m} \\
\left.{ }^{3}\right)\end{array}$ & $\begin{array}{l}\text { Fine } \\
\text { Aggrega } \\
\text { te } \\
\left(\mathrm{Kg} / \mathrm{m}^{3}\right)\end{array}$ & $\begin{array}{l}\text { Coarse } \\
\text { Aggregat } \\
\mathrm{e} \\
\left(\mathrm{Kg} / \mathrm{m}^{3}\right)\end{array}$ & $\begin{array}{l}\text { Water } \\
\left(\mathrm{Kg} / \mathrm{m}^{3}\right)\end{array}$ & $\begin{array}{l}\text { Plasticiz } \\
\text { er } \\
\left(\mathrm{kg} / \mathrm{m}^{3}\right)\end{array}$ \\
\hline 1 & M40 & $\begin{array}{l}351.1 \\
1\end{array}$ & 813.73 & 1197.37 & 158.00 & 2.11 \\
\hline 2 & M20 & $\begin{array}{l}305.0 \\
0\end{array}$ & 797.50 & 1169.26 & 167.40 & 1.83 \\
\hline
\end{tabular}

Concrete cubes of size $150 \mathrm{~mm}$. were cast with varying parameters. Two metal nails were inserted into fresh concrete to act as electrodes. The specimens were then kept in water for curing. However, some specimens were kept in open air for further investigation. Specimens of M40 and M20 grade were cast with $20 \mathrm{~mm}$. and $12.5 \mathrm{~mm}$. downsize coarse aggregates.

Each specimen was tested in surface dry condition using a DC power supply and an ammeter, as shown in Fig. 1. Readings of current were noted down for varying voltages. Similar testing procedure was adopted for AC testing of some specimens, the only change being a Single-phase Autotransformer replacing the DC power supply, as shown in Fig. 2. DC and AC testing were conducted for certain specimens with and without loading conditions (Compressive loading), as shown in Fig.1

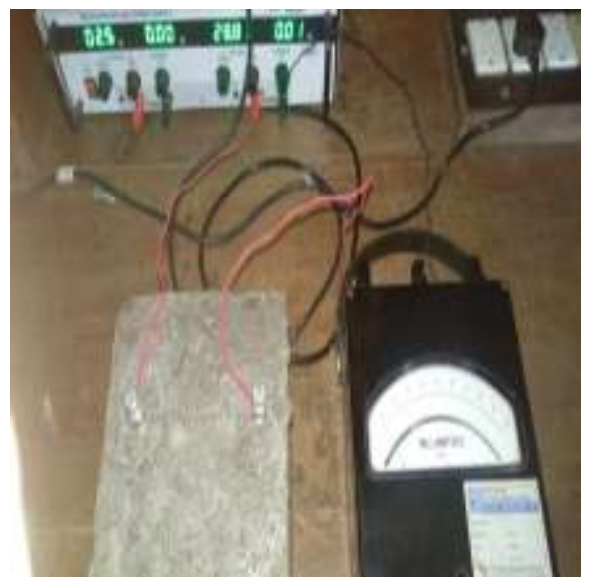

Fig1: Experimental setup for DC testing.

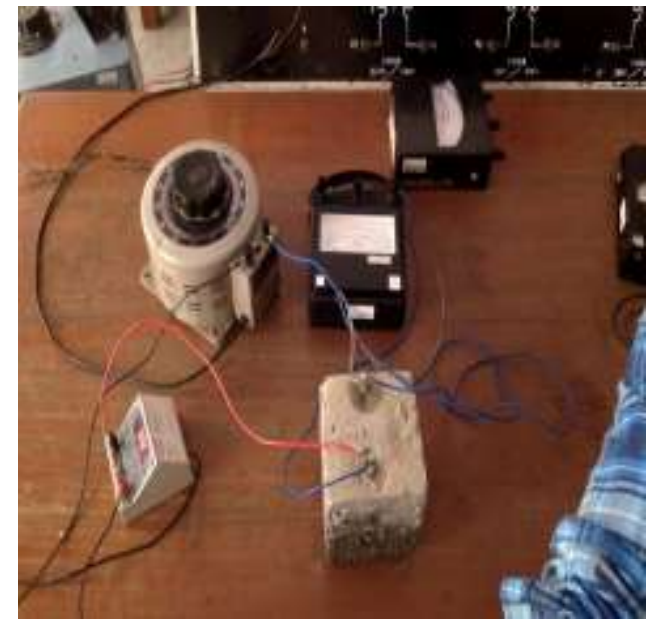

Fig. 2: Experimental setup for AC testing.

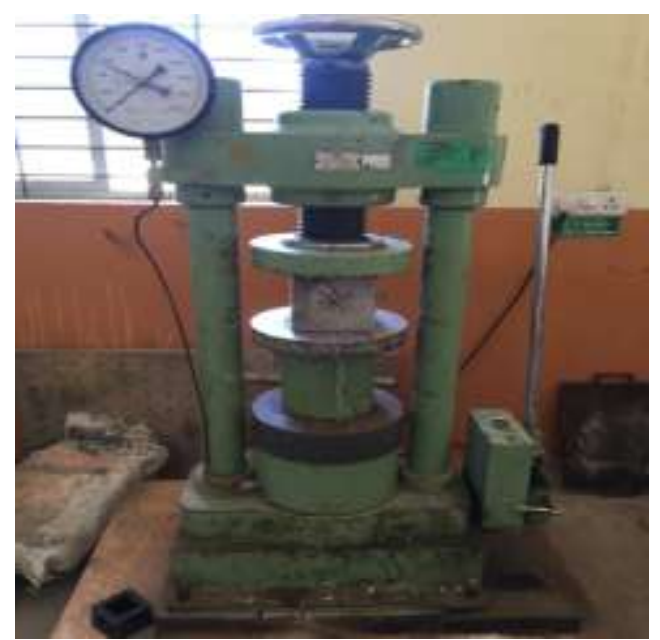

Fig. 3: Compressive loading of specimens.

For AC analysis, the Voltage values were regulated in a fixed manner as shown in Table 3, so as to make the further evaluations easier, as it was important to ensure that all the specimens were tested for the same peak voltage for Peak Current Analysis.

Table 3: AC VOLTAGES

\begin{tabular}{|l|l|l|l|l|l|l|l|l|}
\hline $\begin{array}{l}\text { Sl. } \\
\text { No. }\end{array}$ & 1 & 2 & 3 & 4 & 5 & 6 & 7 & 8 \\
\hline $\begin{array}{l}\text { Voltag } \\
\text { e (V) }\end{array}$ & 20 & 60 & 100 & 160 & 200 & 220 & 240 & 260 \\
\hline $\begin{array}{l}\text { Sl. } \\
\text { No. }\end{array}$ & 9 & 10 & 11 & 12 & 13 & 14 & 15 & \\
\hline $\begin{array}{l}\text { Voltag } \\
\text { e (V) }\end{array}$ & 240 & 220 & 190 & 160 & 100 & 60 & 20 & \\
\hline
\end{tabular}

\section{RESULTS AND DISCUSSION}

The results are presented in the form of Current (I)-Voltage (V) characteristics. 


\subsection{Age of Concrete}

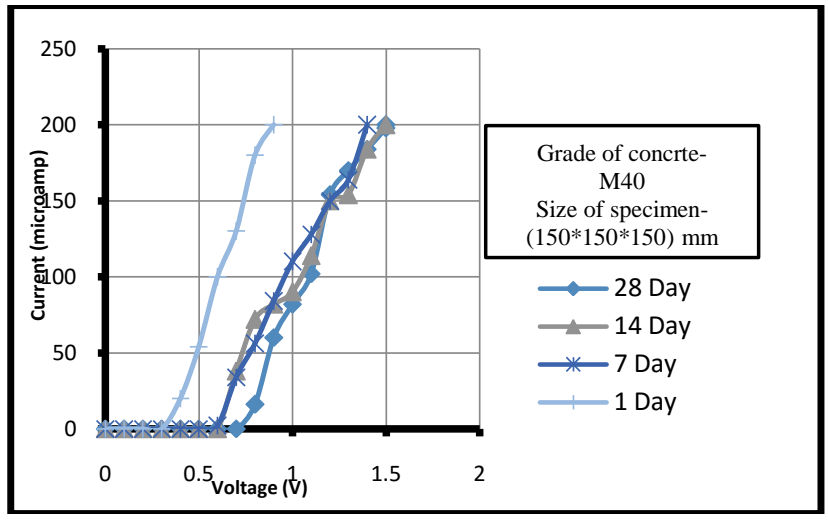

Fig. 4: Variation of I-V Characteristic with age of concrete

Fig. 4 illustrates the variation of I with $\mathrm{V}$, for water cured concrete cubes of size $(150 \times 150 \times 150) \mathrm{mm}$ at the age of 1 , 7,14 and 28 days. It is visible that the threshold voltage of specimen has increased from $0.3 \mathrm{~V}$ at 1 day, to 0.7 at the age of 28 day. Hence, after attaining maturity concrete behaves like a semiconductor.

\subsection{Comparison based on Grade of Concrete}

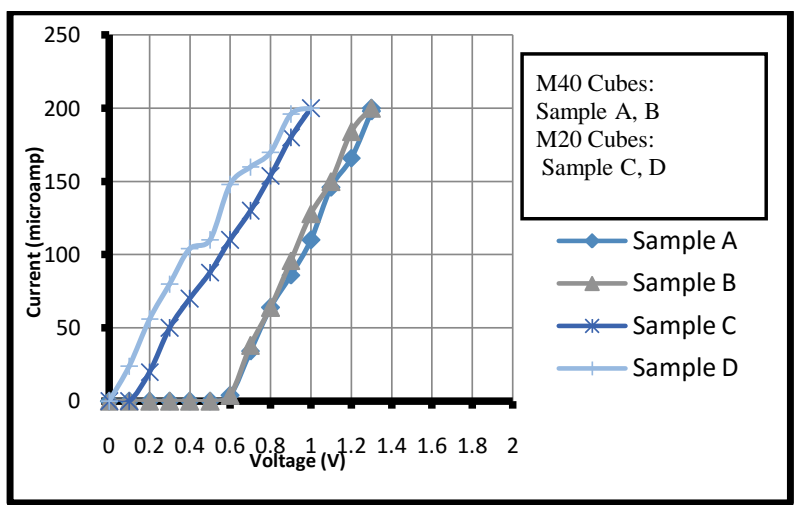

Fig 5: I-V Characteristics for different Grades of concrete

Fig. 5 shows the variation of I with V, for different grades of concrete. It is observed that the conductance of higher grade of concrete is more than that of lower grade. This is due to better pore-refinement in case of higher grade of concrete. Similar natured curves were obtained for the AC analysis as presented above for size of aggregates.

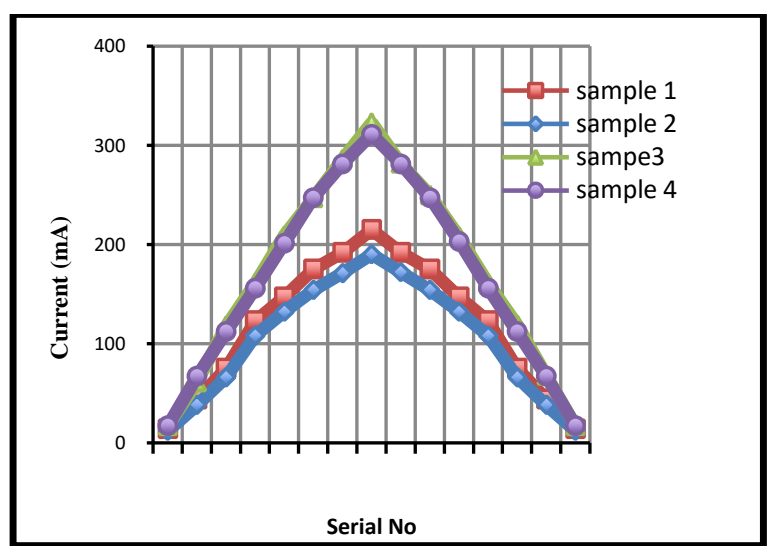

Fig. 6: I-V Characteristics for different Grades of concrete
The plot in Fig. 6 further validates the fact that conductivity increases with better pore refinement i.e. M40 grade of concrete shows lesser impedance compared to M20 grade of concrete.

\subsection{Based on Loading and Unloading Conditions}

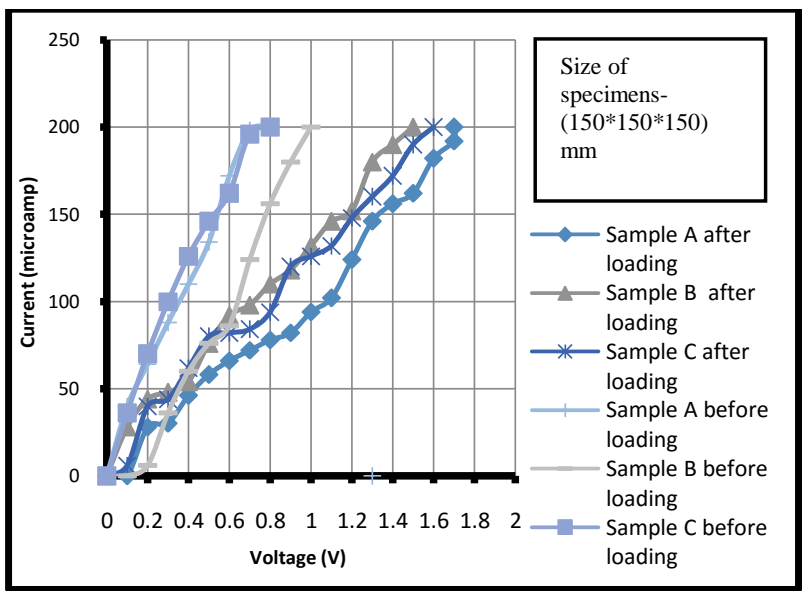

Fig. 7: I-V Characteristics for loading and unloading conditions

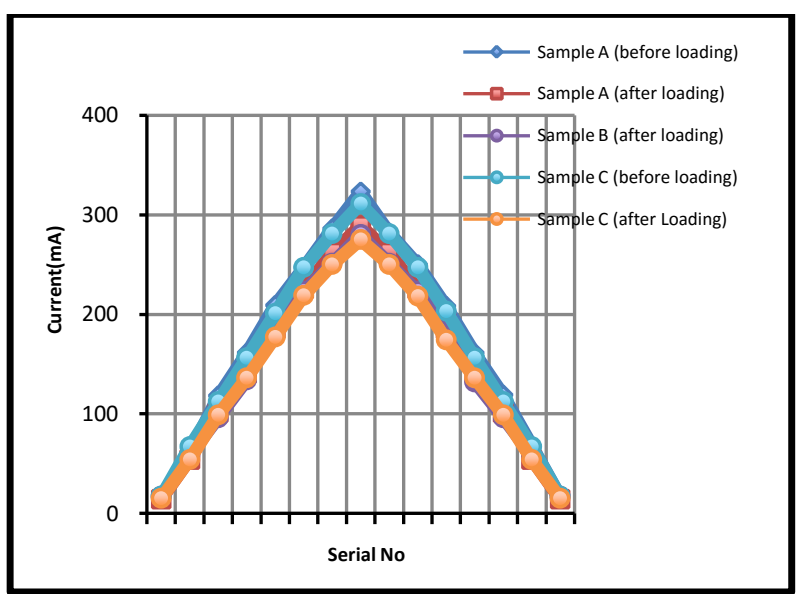

Fig. 8: I-V Characteristics for loading and unloading conditions

From Fig. 7 and 8, it is evident that the specimens when tested before loading showed higher conductance, to ones tested after loading. The nature of loading was compressive. And a substantial drop was observed in the impedance as well as resistance values. When tested under AC and DC supply respectively. The application of load was a deliberate step to introduce cracks in the concrete. 


\subsection{Based on Curing Conditions}

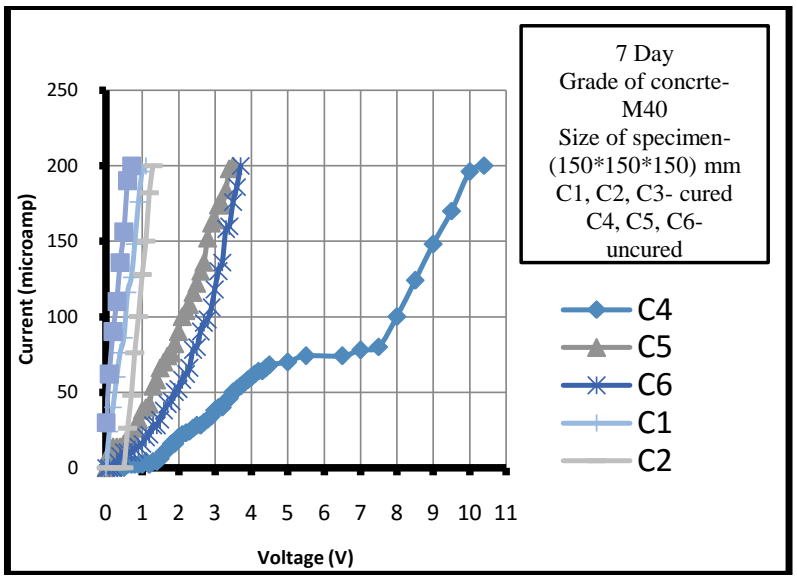

Fig. 9: I-V Characteristics for cured and uncured concrete

As it is clearly visible from the plot that conductivity in cured blocks is much higher than that of uncured ones. Lower conductivity in uncured blocks is the further validation of assumption acquired from the literature that main force driving electric current in concrete is presence of pore water.

\subsection{Based on Size of Course Aggregate Used}



. Fig. 10: I-V Characteristics based on aggregate size

The plot shows that higher the aggregate size higher will be the conductivity of concrete. This is better explained by the following $\mathrm{AC}$ analysis of the same specimen.

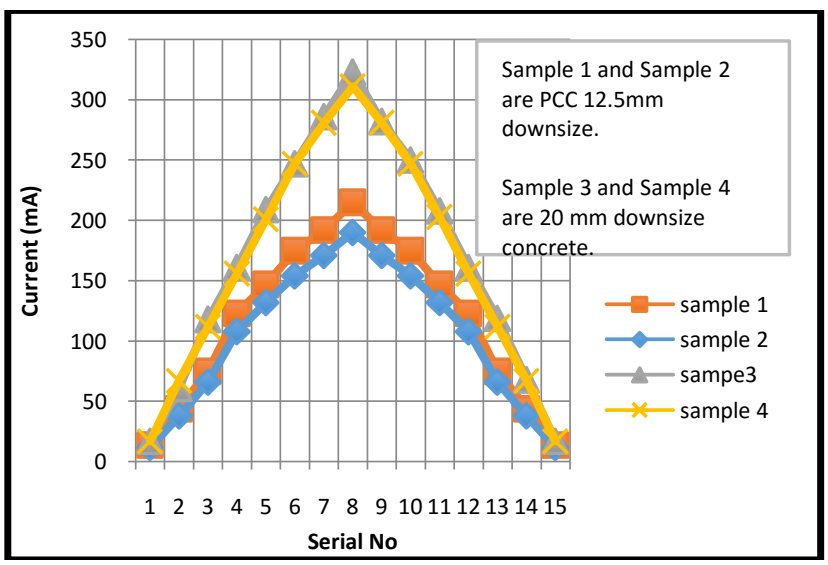

Fig. 11:I-V Characteristics based on aggregate size
It can be inferred that the conductance of slag sand was the highest among slag, natural and manufactured sand. This may be because of higher steel content in slag from industries, resulting in higher conductivity. Natural sand is more conductive than the manufactured ones. This can be justified by the fact that natural sand is nothing but river deposits which may not have uniform grading resulting in more amounts of voids which in turn direct towards more water content in pores. Moreover river deposits might have gone through the segregation of conductive ions that are present in the river.

\section{INFERENCES}

One of the major applications of the AC analysis of specimens was the peak current analysis, which in a way showed what maximum current could pass through the specimens. The maximum feasible voltage for the experiment was 260V. A graph, shown in Fig. 13, was plotted for studying the peak current through the specimen.

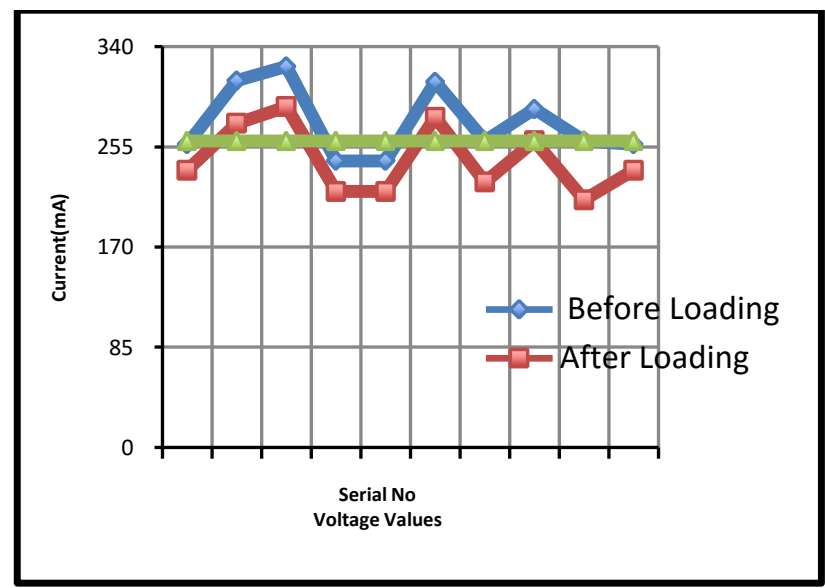

Fig. 14: Peak current analysis for before and after loading Conditions

It was observed that for a specimen tested before load showed a major drop in the current passing at the peak voltage. This drop was further studied as a RC circuit. And further calculations proved that capacitance after load was less than capacitance before load which is due to the increase in depth of already existing or newly propagated cracks. The calculation shown below proves the fact.

From the graphs discussed in results and discussions, there are two important inferences:

1. $\mathbf{R}_{1}$ (Resistance before loading) $<\mathbf{R}_{2}$ (Resistance after loading)

2. $\mathrm{Z}_{1}$ (Impedance before loading) $<\mathrm{Z}_{2}$ (Impedance after loading)

\section{CONCLUSION}

The following conclusions were drawn:

- Concrete shows semiconductor properties; however further evaluation showed that the concrete bulk was behaving as a combination of resistances and capacitances. 
- There was a continuous decrease in conductivity with ageing; however the semi-conductor nature was prominent, though the threshold voltage kept on increasing.

- Specimens with larger aggregate size showed less resistance as well as impedance.

- Better pore-refinement for a higher grade of concrete ensured higher conductivity.

- Uncured concrete specimens showed less conductivity compared to cured ones, owing to less pore water.

- The drawbacks of dc supply like ion deposition was not visible in case of ac supply, and the results concluded above were better observed in their AC plots respectively.

- For specimens tested under load and DC current supply, the resistance before loading was always less than the resistance after loading.

- Similarly, for AC supply, the impedance before loading was always less than the impedance after loading.

- Peak current analysis showed that, there was a substantial drop in the maximum current passing through the specimen when under load.

\section{ACKNOWLEDGEMENT}

1) We express our sincere regards and heartfelt gratitude to Dr. Radhakrishna, Associate Professor and Dean, Department of Civil Engineering, RVCE under whose guidance this study was planned, executed and completed. His encouragement, interest and ideas were source of inspiration and motivation for successful completion of this work.

2) We are grateful to Mr. Paman, Mr. Somanath and Mr. Shivapraksh for helping in conducting important experimental works.

3) We are also grateful to our parents, our family members and all our friends for their timely support and encouragement throughout the project.

4) Above all we wish to express our heartfelt thanks to the almighty GOD, for giving us opportunity to do this course.

\section{REFERENCES}

[1].Amir M. Alani and MortezaAboutalebi (2015) Mechanical properties of fibre reinforced concrete- A comparative experimental study. International Journal of Civil, Architectural Science and Engineering World Academy of Science, Engineering and Technology 7 (9): 203-208

[2].Blitz J and Simpson G (1996) Ultrasonic Methods of Non-Destructive Testing. Springer, Netherlands

[3].Blitz J and Simpson G (1995) Ultrasonic Methods of Non- destructive Testing. Springer, Netherlands

[4]. Calleja(1953)Determination of setting and hardening time of high-alumina cement by electrical resistance techniques. Journal of the American Concrete Institute 50 (11): 249-256
[5]. Hansson and Hansson (1983) Electrical resistivity measurement of port-land cement based materials. Cement and Concrete Research 13 (5):675-683

[6]. Lasse M Heikkinen, TanjaVilhunen, Robert M West, Marko Vauhkonen (2002) Simultaneous Reconstruction of Electrode Contact Impedances and Internal Electrical Properties: II. Laboratory Experiments. Measurement Science and Technology, 13:1855-1861

[7].Hammond E and Robson TD (1955) Comparison of Electrical Properties of Various Cements and Concretes. The Engineer 199:114-115.

[8].Hui Li, Hui-gang Xiao, Jin-ping Ou (2006) Effect of Compressive Strain on Electrical Resistivity of Carbon Black-filled Cement-based Composites. Cement and Concrete Composites 28:824-828

[9]. J.W. Mayer and S.S. Lau (1990) Electronic materials science: For integrated circuits in $\mathrm{Si}$ and Ga. Macmillan Publication Co., New YorkMichelle Ho (2014) Electrically Conductive Concrete. Presented at University of Houston Cullen College of Engineering

[10]. Michelle R. Nokken and R. Doug Hooton (2006) Electrical conductivity testing. Concrete International 28 (10):58-63

[11]. Rajat Srivastava (2015) Study on Causes of Cracks \& its Preventive Measures in Concrete Structures. International Journal of Engineering Research and Applications 5 (5):119-123.

[12]. Kevin L. Rens, Terry J. Wipf, F. Wayne Klaiber (1997) Review of nondestructive evaluation techniques of civil infrastructure. Journal of Performance of Constructed Facilities 11(4):152-160

[13]. Spragg R, Nantung T, Weiss J (2013) ConcreteDurability and the Value of Electrical testing .Presented at the $99^{\text {th }}$ Annual Purdue Road School, Purdue School of Civil Engineering, west Lafayette, IN

[15]. Vilhunen T, Kaipio J P, Vauhkonen P J, Savolainen T andVauhkonen M (2012) Simultaneous reconstruction of electrode contact impedances and internal electrical properties. Measurement Science and Technology 13 (12):1848-1854

[16].Giurgiutiu V (2005) Structural health monitoring: with piezoelectric wafer active sensors. Presented at 16th International Conference of Adaptive Structures and Technologies ICAST-2005, Paris, France 